\title{
26. SOME MAGNETIC PROPERTIES OF SPECIMENS FROM HOLE 332B AND SITES 334 AND 335, AND CORRESPONDING ANALYSIS IN TERMS OF EMPLACEMENT MODE
}

\author{
B.B. Ellwood and N.D. Watkins, Graduate School of Oceanography, University of Rhode Island, \\ Kingston, Rhode Island
}

\begin{abstract}
The anisotropy of magnetic susceptibility (AMS), bulk susceptibility, and directions and stability of remanent magnetism of 37 basalt specimens from Hole 332B and Sites 334 and 335 have been measured.

The remanent magnetism shows that at Site 335 , a single stable reversed polarity is recorded between 467 and 517 meters depth. At Site 334 , a reversed polarity body occurs between normal polarity units at 320 meters depth. Similarly, a normal polarity body probably occurs between reversed units at 466 meters in Hole 332B which otherwise appears to be reversely magnetized throughout the 156 to 590 meters depth. Below 590 meters in Hole 332B, there exist three samples with stable anomalously low inclinations of remanent magnetism, interspersed by a normally magnetized unit at 610 meters depth. We suspect that pillow segments which have rolled after reaching the blocking temperature may be represented by these three units with the opposite polarity body representing an intrusion.

The AMS data may (as far as we know), with one definite exception, represent only single specimens from separate bodies, and are thus not reliably analyzed in terms of our proposed emplacement mode diagnosis techniques. According, however, to an AMS parameter $(F)$ designed to emphasize maximum axis elongation, and to conclusions derived from a previous empirical application of $F$ to many bodies of known emplacement mode, cores from the three holes are dominantly extrusive in origin.

Only five specimens are diagnosed as intrusive. None of these possess anomalous inclination of remanent magnetism which we believe can most readily occur in extrusives. Two of these five specimens appear to possess the appropriate "intrusive" AMS signature because of an unusually well defined zone of crystal settling and growth towards the base of what is otherwise probably an extrusive body between 199 and 204 meters depth in Hole 332B. Thus our use of AMS to identify emplacement modes cannot be used with confidence in single samples showing evidence of pronounced crystal settling.
\end{abstract}

\section{INTRODUCTION}

In addition to participating in measurement of conventional paleomagnetic properties of DSDP igneous rocks, we have recently given thought to the problem of distinguishing emplacement modes.

Anisotropy of magnetic susceptibility (AMS), which is a tensor of the second rank relating an inducing magnetic field to an induced intensity of magnetization, is related to magnetic mineral shape. We believe AMS can therefore assist in identifying the degree to which igneous bodies suffer preferred crystal alignment or growth, and we have demonstrated a strong tendency for intrusive igneous rocks to have such properties (Ellwood and Watkins, 1973). AMS data are conventionally expressed as a triaxial ellipsoid with major $(K a)$, intermediate $(K b)$, and minor $(K c)$ axes representing the corresponding susceptibility directions and magnitudes, respectively.
Two possible methods for determining emplacement modes of basaltic materials recovered from DSDP cores have emerged from our study of AMS variations in single igneous bodies (Ellwood and Watkins, 1973; Ellwood, 1975). First, it appears that intrusive units much more frequently exhibit strongly preferred AMS axis alignments, while extrusives appear to only rarely have such alignments. A second method has resulted from the development of a new AMS parameter $F$, where

$$
F=\frac{K a^{\prime}}{\sqrt{K b^{\prime} \times K c^{\prime}}}
$$

and $K a^{\prime}, K b^{\prime}$, and $K c^{\prime}$ are tensor magnitudes calculated for a standard volume susceptibility of $(\chi) 1.0 \times 10^{-3}$ cgs units. $F$ is therefore designed to emphasize long axis 
magnitudes, without any between-sample variation being obscured by variation of $\chi$. Computation of $F$ for 312 separate specimens from known intrusive and extrusive bodies shows that when $F$ is $\geq 1.040$, intrusives can be successfully distinguished from extrusive bodies with an $80 \%$ confidence (Ellwood, 1975). Therefore dual searches for both preferred planes of AMS and $F$ magnitudes above 1.040 provide means to diagnose the presence of intrusive bodies in DSDP cores. An important factor in these proposed techniques is the need for several samples from a single body, since not only would preferred planes remain undefinable, but as with almost all experimental methods, inferences employing data from single specimens can always be subject to doubt.

\section{METHODS}

Thirty-seven specimens of $2.5 \mathrm{~cm}$ diameter were drilled normal to the vertical axes of the three holes (332B, 334, and 335). Seven of these specimens were drilled from a single body between 199.0 and 204.5 meters depth within Hole 332B, according to the shipboard report. No other indication of the number of specimens within separate bodies has been provided to us. All specimens were sliced into samples of $2.2 \mathrm{~cm}$ length.

The remanent magnetism of all specimens was measured on a Digico spinner magnetometer. Demagnetization in alternating magnetic fields of 100 and 200 oe was carried out in order to minimize unstable components. AMS was measured on a low field torque meter, similar to that described by Stone (1963). Volume susceptibility was measured on a $300-\mathrm{Hz}$ susceptibility bridge (Collinson, et al., 1963).

\section{RESULTS}

Table 1 presents the magnetic susceptibility and AMS results for all specimens from Hole $332 \mathrm{~B}$ and Sites 334 and 335. Remanent magnetization data are given in Chapters 2, 4, and 5 (this volume).

\section{DISCUSSION}

\section{Remanent Magnetism}

The material between 467 and 517 meters depth at Site 335 provides an unusually consistent reversed polarity inclination at all levels. Assuming that no great time span is represented, this consistency of inclination (if not polarity) is to be expected in view of the high stability indices, which show that no more than $15 \%$ of the remanent intensity is removed by a demagnetizing field of 100 oe, and an average less than $30 \%$ is removed at 200 oe.

Specimens from Site 334 and Hole 332B, however, have highly variable inclinations and stabilities. We conclude from these data that mixed polarities are present at Site 334 (where a normal polarity unit exists between reversed polarity units at $320 \mathrm{~m}$ depth), and that in Hole 332B the material between 156 and 590 meters depth is, with the exception of a unit at 466 meters depth, of reversed polarity. Inclinations are consistently lower than the present axial dipole value. The 100 meters beneath 466 meters have relatively stable but very shallow inclinations which are most readily attributed to the distorting effect of pillows continuing to roll and cool after reaching the blocking temperature. We prefer this explanation as being more probable than the recording of a transition of polarity or excursion of the geomagnetic field.

\section{Susceptibility Anisotropy (All Specimens)}

With only a few exceptions, $F$ in cores is below 1.040 which, using the empirically derived criterion (Ellwood, 1975), is indicative of extrusive emplacement mode. These assignments (Table 1) are not made with great confidence, since with only one exception do we have any guide to the presence of separate bodies, which would allow us to detect preferred planes of anisotropy, thus providing an independent check. The anisotropy is above $8.8 \%$ in only seven samples, and all the specimens diagnosed as intrusive fall into this category, but we believe this is not necessarily indicative only of the intrusive mode. Our earlier preferred explanation of the anomalously low inclinations of remanent magnetism of three of the four lowest specimens in Hole 332B appears reasonable when examining the $F$ values (Table 1): the sampled parts of three extrusive bodies could conceivably all have been below the blocking temperature as the exterior segments continued to roll, while the normal polarity unit (possessing an inclination of about $40^{\circ}$ ) is assigned to an intrusive and therefore later (opposite polarity), and more regular emplacement. Certainly none of the specimens diagnosed as intrusive in any of the three sites possess grossly anomalous remanent inclinations, and this is to be expected if our preferred explanation of the source of anomalous stable inclination is correct. On the other hand, there is no particular reason why rolling should produce inclination distorting to such similar low values in three separate specimens.

\section{Susceptibility Anisotropy (Single Unit)}

In Figure 1 we show the $F$ values, a measure of remanent magnetic stability $\left(j_{100} / J_{\text {nrm }}\right)$, and magnetic susceptibility $(\chi)$ for the seven specimens, which according to the shipboard scientists, comprise a single body between 199.0 and 204.5 meters depth in Hole 332B. Not plotted are the directions of AMS, which are indicated in Table 1; these are all less than $15^{\circ}$ in the maximum, mostly less than $25^{\circ}$ in the intermediate, and dominantly vertical in the minimum, showing the existence, therefore, of a somewhat preferred plane of AMS with the minimum axes forming the "pole." This could therefore possibly indicate the presence of an intrusive body, but in examining the $F$ values in Figure 1a, we see that $F$ is consistent with an intrusive nature only in the lower parts of the body. We would therefore conclude that the AMS data alone provide inconclusive results insofar as the emplacement mode for the unit involved is concerned.

The systematic variation of $J_{100} / J_{\text {nrm }}$ and $\chi$ with depth in the body (Figures $1 \mathrm{~b}$ and $1 \mathrm{c}$ ) is best explained as being the result of an increase in titanomagnetite crystal size with increasing depth in the body. The larger crystal size leads to a decrease in coercivity, and an increase in bulk titanomagnetite content. These 
TABLE 1

Anisotropy of Magnetic Susceptibility Data for Basalt Specimens from Hole 332B, and Sites 334, 335, DSDP Leg 37

\begin{tabular}{|c|c|c|c|c|c|c|c|c|c|c|c|c|c|c|}
\hline $\begin{array}{c}\text { Sample } \\
\text { (Interval in } \mathrm{cm} \text { ) }\end{array}$ & Depth (m) & $x \times 10^{-4}(\mathrm{cgs})$ & $K a \times 10^{-4 a}$ & $K b \times 10^{-4 b}$ & $K c \times 10^{-4 c}$ & Dmax & Imax & Dint & Iint & Dmin & Imin & $\% \mathrm{AN}$ & $\mathrm{F}$ & "Emplacement" $d$ \\
\hline \multicolumn{15}{|l|}{ Hole 332B } \\
\hline $2-4-54$ & 156.5 & 1.9 & 2.01 & 1.98 & 1.94 & 176.5 & -11.7 & 83.3 & -15.2 & 302.4 & -70.6 & 3.8 & 1.005 & E \\
\hline $3-1-18$ & 199.2 & 1.3 & 1.29 & 1.27 & 1.26 & 7.4 & -7.6 & 98.5 & -8.7 & 236.8 & -78.4 & 2.3 & 1.003 & $\mathrm{E}$ \\
\hline $3-1-120$ & 200.2 & 1.1 & 1.11 & 1.10 & 1.09 & 288.0 & -1.1 & 18.2 & -10.1 & 192.1 & -79.9 & 2.5 & 1.002 & $\mathrm{E}$ \\
\hline $3-2-80$ & 201.3 & 1.1 & 1.08 & 1.07 & 1.06 & 239.9 & -5.3 & 331.2 & -13.8 & 129.2 & -75.2 & 2.1 & 1.002 & E \\
\hline $3-3-46$ & 202.5 & 1.6 & 1.77 & 1.66 & 1.64 & 139.3 & -14.8 & 45.7 & -13.1 & 275.9 & -70.0 & 8.2 & 1.013 & $\mathrm{E}$ \\
\hline $3-3-133$ & 203.3 & 4.5 & 4.86 & 4.55 & 4.45 & 207.6 & -0.6 & 117.2 & -32.5 & 298.5 & -57.5 & 9.1 & 1.036 & E \\
\hline $3-4-27$ & 203.8 & 5.9 & 6.92 & 6.41 & 5.83 & 176.0 & -3.6 & 84.4 & -23.4 & 274.3 & -66.3 & 17.0 & 1.079 & I \\
\hline $3-4-64$ & 204.1 & 4.8 & 5.45 & 5.20 & 4.72 & 124.5 & -10.7 & 31.2 & -17.2 & 245.0 & -69.6 & 13.9 & 1.048 & I \\
\hline $9-3-103$ & 336.0 & 1.2 & 1.24 & 1.24 & 1.24 & 5.7 & -12.5 & 125.8 & -66.2 & 271.1 & -19.9 & 0.6 & 1.001 & E \\
\hline $11-1-115$ & 361.7 & 15.0 & 15.33 & 15.11 & 14.99 & 84.7 & -65.8 & 176.1 & -0.6 & 266.3 & -24.2 & 2.3 & 1.029 & $\mathrm{E}$ \\
\hline $13-1-137$ & 380.7 & 3.3 & 3.47 & 3.43 & 3.27 & 140.9 & -7.1 & 233.4 & -19.7 & 32.0 & -69.0 & 5.6 & 1.011 & $\mathrm{E}$ \\
\hline $20-2-34$ & 447.4 & 1.3 & 1.31 & 1.29 & 1.26 & 188.6 & -31.1 & 352.9 & -57.9 & 94.3 & -7.1 & 4.0 & 1.004 & $\mathrm{E}$ \\
\hline $22-1-97$ & 466.0 & 1.7 & 1.72 & 1.71 & 1.68 & 251.8 & -80.4 & 96.6 & -8.7 & 6.0 & -4.0 & 2.8 & 1.003 & $\mathrm{E}$ \\
\hline $22-2-22$ & 466.7 & 0.6 & 0.61 & 0.60 & 0.59 & 54.9 & -67.1 & 187.9 & -16.1 & 282.6 & -15.9 & 1.8 & 1.001 & $\mathrm{E}$ \\
\hline $23-1-100$ & 475.5 & 1.4 & 1.47 & 1.46 & 1.41 & 30.6 & -1.5 & 122.2 & -45.5 & 299.2 & -44.5 & 4.2 & 1.003 & $\mathrm{E}$ \\
\hline $25-4-51$ & 498.5 & 2.3 & 2.33 & 2.32 & 2.28 & 186.0 & -29.5 & 342.9 & -58.5 & 90.1 & -10.3 & 1.8 & 1.002 & $\mathrm{E}$ \\
\hline $28-2-18$ & 523.7 & 0.9 & 0.89 & 0.87 & 0.85 & 94.6 & -54.3 & 269.2 & -35.5 & 1.0 & -2.6 & 4.7 & 1.003 & E \\
\hline $29-1-69$ & 532.2 & 0.8 & 0.79 & 0.76 & 0.73 & 358.7 & -78.7 & 89.0 & -0.1 & 179.0 & -11.3 & 8.0 & 1.005 & $\mathrm{E}$ \\
\hline $29-2-9$ & 533.9 & 1.5 & 1.55 & 1.54 & 1.52 & 78.3 & -15.6 & 320.2 & -59.3 & 176.0 & -25.7 & 1.8 & 1.002 & E \\
\hline $30-1-46$ & 541.5 & 1.0 & 0.97 & 0.97 & 0.94 & 5.9 & -86.7 & 272.9 & -0.2 & 182.9 & -3.3 & 3.0 & 1.002 & E \\
\hline $35-2-62$ & 590.6 & 1.2 & 1.19 & 1.18 & 1.14 & 55.4 & -33.3 & 183.3 & -43.1 & 304.3 & -28.8 & 4.4 & 1.003 & E \\
\hline $36-2-3$ & 599.5 & 1.7 & 1.91 & 1.75 & 1.66 & 261.4 & -7.2 & 352.5 & -8.9 & 133.3 & -78.5 & 14.4 & 1.021 & $\mathrm{E}$ \\
\hline $36-2-81$ & 600.3 & 1.4 & 1.57 & 1.49 & 1.44 & 344.7 & -11.0 & 253.7 & -5.1 & 139.3 & -77.9 & 8.8 & 1.011 & E \\
\hline $37-3-11$ & 610.6 & 8.2 & 9.16 & 8.22 & 8.02 & 192.4 & -21.0 & 288.1 & -14.5 & 50.3 & -64.1 & 13.9 & 1.105 & I \\
\hline $44-3-144$ & 678.4 & 5.0 & 5.04 & 5.03 & 4.96 & 119.1 & -45.2 & 220.6 & -11.1 & 321.0 & -42.7 & 1.5 & 1.004 & $\mathrm{E}$ \\
\hline \multicolumn{15}{|l|}{ Site 334} \\
\hline $19-2-6$ & 292.6 & 2.3 & 2.32 & 2.31 & 2.29 & 139.1 & -26.2 & 322.2 & -63.7 & 299.7 & -1.2 & 1.0 & 1.001 & E \\
\hline $22-1-57$ & 320.1 & 0.5 & 0.47 & 0.46 & 0.45 & 162.9 & -11.7 & 253.6 & -3.6 & 0.3 & -77.8 & 4.0 & 1.002 & E \\
\hline $22-2-52$ & 321.5 & 32.0 & 32.39 & 31.85 & 29.22 & 129.1 & -81.6 & 314.5 & -8.3 & 224.4 & -0.8 & 9.9 & 1.244 & I \\
\hline $22-2-85$ & 321.9 & 34.0 & 35.11 & 34.22 & 32.08 & 60.2 & -28.3 & 232.8 & -61.5 & 328.5 & -3.1 & 8.9 & 1.234 & I \\
\hline \multicolumn{15}{|l|}{ Site 335} \\
\hline $7-1-85$ & 467.9 & 0.5 & 0.54 & 0.53 & 0.52 & 155.2 & -15.7 & 349.5 & -73.8 & 246.2 & -3.8 & 3.5 & 1.001 & E \\
\hline $8-2-24$ & 478.2 & 0.8 & 0.77 & 0.74 & 0.73 & 216.7 & -67.0 & 340.7 & -13.4 & 75.3 & -18.4 & 5.5 & 1.004 & $\mathrm{E}$ \\
\hline $8-2-94$ & 478.9 & 1.0 & 0.98 & 0.98 & 0.97 & 21.2 & -71.1 & 157.4 & -13.9 & 250.5 & -12.6 & 1.3 & 1.001 & $\mathrm{E}$ \\
\hline $8-4-20$ & 481.2 & 1.1 & 1.08 & 1.07 & 1.03 & 0.4 & -21.1 & 147.5 & -65.3 & 265.6 & -12.2 & 5.1 & 1.003 & $\mathrm{E}$ \\
\hline $10-3-100$ & 499.5 & 1.0 & 0.99 & 0.98 & 0.97 & 95.7 & -65.5 & 254.9 & -23.1 & 348.3 & -7.8 & 2.1 & 1.001 & E \\
\hline $10-6-4$ & 503.0 & 2.0 & 2.05 & 2.03 & 2.03 & 120.0 & -27.1 & 330.7 & -59.3 & 217.0 & -13.4 & 1.2 & 1.002 & E \\
\hline $11-1-62$ & 505.6 & 1.5 & 1.49 & 1.45 & 1.43 & 93.2 & -35.7 & 247.4 & -51.4 & 353.8 & -12.7 & 3.8 & 1.005 & E \\
\hline $12-2-139$ & 517.4 & 1.3 & 1.35 & 1.33 & 1.31 & 111.4 & -33.4 & 245.6 & -46.6 & 4.1 & -24.3 & 2.8 & 1.003 & E \\
\hline
\end{tabular}

${ }^{\mathrm{a}}$ Maximum magnitude in cgs units.

$\mathrm{b}_{\text {Intermediate magnitude in cgs units. }}$

${ }^{c}$ Minimum magnitude in cgs units.

$\mathrm{d}_{\mathrm{E}}=$ extrusive; $\mathrm{I}$ = intrusive; note discussion in text which stresses the problem of assigning high confidence to $\mathrm{E}$ or $\mathrm{I}$ in the absence of definite multiple sampling of each body. 

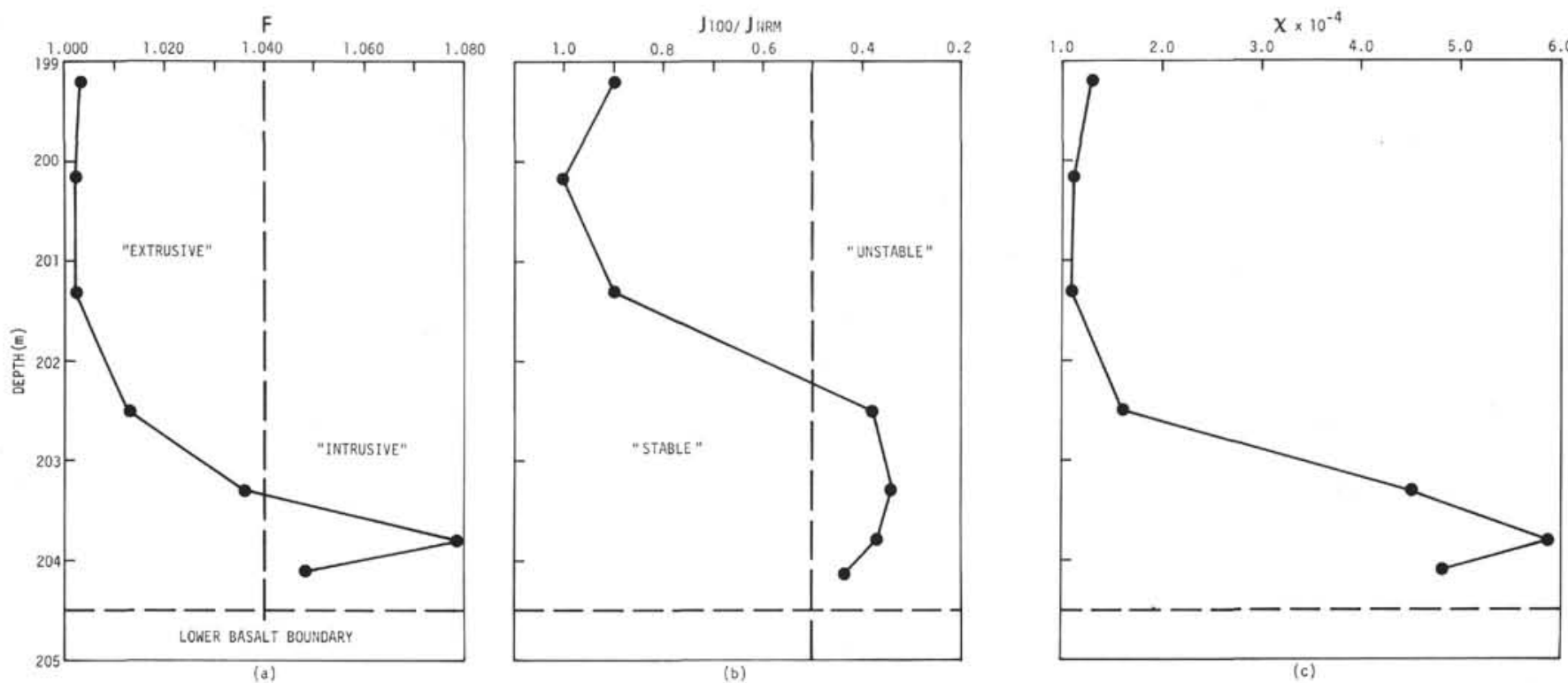

Figure 1. Variations through a single basalt body as a function of depth in meters of (a) AMS F values. Vertical dashed line separates extrusives from intrusives at the $80 \%$ confidence level (Ellwood, in press). (b) $J_{100} / J_{\text {nrm. }}$ Vertical dashed line separates relatively stable from relatively unstable fields. (c) $X \times 10^{-4}$, volume susceptibility in cgs units.

data, therefore, provide an indication of crystal settling in the body, or prolonged crystal growth (resulting from sustained higher temperatures). Either explanation is possible for an extrusive, but an intrusive would satisfy only the first condition, since asymmetry of cooling rates is unlikely in a sill, for example. Thus, on the average, we would favor, but cannot be certain of, an extrusive mode for the body, with an unusually well defined late-stage crystal settling and growth in the lower parts being the source of AMS data possessing "intrusive" character, particularly in the $F$ values. This argument emphasizes the critical need for several samples from each body, and the dual approach, if our AMS techniques are to be used with confidence in distinguishing intrusive from extrusive bodies. On the other hand, a simple petrographic examination can reveal the presence of crystal settling, and it would therefore appear that when such settling is present, the AMS techniques we propose should not be used for diagnosing emplacement.

\section{REFERENCES}

Collinson, D.W., Stone, B.D., and Molyneux, L., 1963. A total and anisotropic magnetic susceptibility meter: J. Sci. Instrum., v. 40, p. 310-312.

Ellwood, B.B., 1975. Analysis of emplacement mode in basalt from DSDP Holes $319 \mathrm{~A}$ and 321 using anisotropy of magnetic susceptibility: J. Geophys. Res., v. 80 , p. $4805-$ 4808.

Ellwood, B.B. and Watkins, N.D., 1973. Anisotropy of magnetic susceptibility and emplacement modes of submarine igneous rocks: Am. Geophys. Un. Trans., v. 54, p. 95-96.

1975. Diagnosis of emplacement mode of basalt in Hole 319A and Site 321. In Hart, S.R., Yeats, R.S., et al., Initial Reports of the Deep Sea Drilling Project, Volume 34: Washington (U.S. Government Printing Office), p. $495-500$.

Stone, D.B., 1963. Anisotropic magnetic susceptibility measurements on a phonolite and on a folded metamorphic rock: Geophys. J., v. 7, p. 375-390. 